\title{
Inhibition of DMH-DSS-induced colorectal cancer by liposomal bovine lactoferrin in rats
}

\author{
YUKA SUGIHARA $^{1 *}$, XIAOXU ZUO $^{2 *}$, TAKASHI TAKATA ${ }^{3}$, SHENGJIAN JIN $^{2}$, MUTUMI MIYAUTI $^{3}$, \\ ATUSI ISIKADO ${ }^{4}$, HIROMICHI IMANAKA ${ }^{4}$, MASAAKI TATSUKA $^{5}$, GUANGYING QI $^{1,2}$ and FUMIO SHIMAMOTO ${ }^{1}$ \\ ${ }^{1}$ Department of Health Sciences, Prefectural University of Hiroshima, Minami, Hiroshima 734-8558, Japan; \\ ${ }^{2}$ Department of Pathology and Physiopathology, Guilin Medical University, Guilin, Guangxi Autonomous Region 541004, \\ P.R. China; ${ }^{3}$ Department of Oral and Maxillofacial Pathobiology, Hiroshima University Graduate School of Biomedical \\ Sciences, Hiroshima 734-8553; ${ }^{4}$ R\&D Division, Sunstar Inc., Osaka 569-1195; ${ }^{5}$ Department of Life Sciences, \\ Faculty of Life and Environmental Sciences, Prefectural University of Hiroshima, Hiroshima 727-0023, Japan
}

Received May 10, 2016; Accepted March 9, 2017

DOI: $10.3892 / \mathrm{ol} .2017 .6976$

\begin{abstract}
Bovine lactoferrin (bLF) is a multifunctional protein with anti-inflammatory, antibacterial, antiviral, anti-tumour and immunoregulatory effects. The present study was conducted to evaluate the anti-inflammatory and anti-tumour effects of liposomal bLF (LbLF) in a 1,2-dimethylhydrazine $(\mathrm{DMH}) /$ dextran sulphate sodium (DSS)-induced model of carcinogenesis in F344 rats. F344 rats were randomly divided into three groups: Control (water), 500 or $1,000 \mathrm{mg} / \mathrm{kg} / \mathrm{day}$ LbLF; additionally, the rats were injected with DMH $(20 \mathrm{mg} / \mathrm{kg})$ once per week for 8 consecutive weeks, after one week of drinking water containing 1\% DSS. All rats were sacrificed at 25 weeks. The tissues were examined for the presence of aberrant crypt foci (ACF) and subjected to histopathological analysis. Additionally, human colon cancer cells were utilised to investigate the effect of LbLF on proliferation and inflammation. Rats from the 500 and $1,000 \mathrm{mg} / \mathrm{kg} / \mathrm{day} \mathrm{LbLF}$ groups harboured significantly fewer colon ACF, adenomas and adenocarcinomas than the rats from the control group. Lastly, it was demonstrated that LbLF inhibits cell growth and TNF- $\alpha$ mRNA expression. These data support the hypothesis that LbLF affects colorectal carcinogenesis by suppressing inflammation and cell proliferation in rats.
\end{abstract}

Correspondence to: Dr Guangying Qi, Department of Pathology and Physiopathology, Guilin Medical University, 109 North 2nd Huan Cheng Road, Qixing, Guilin, Guangxi Autonomous Region 541004, P.R. China

E-mail: 2608689827@qq.com

Professor Fumio Shimamoto, Department of Health Sciences, Prefectural University of Hiroshima, 1-1-71 Ujina-Higashi, Minami-ku, Hiroshima 734-8558, Japan

E-mail: simamoto@pu-hiroshima.ac.jp

${ }^{*}$ Contributed equally

Key words: liposomal bovine lactoferrin, colorectal cancer, 1,2-dimethylhydrazine, dextran sulphate sodium

\section{Introduction}

Colorectal cancer (CRC) is one of the most prevalent and highly diagnosed types of cancer and is a common cause of cancer-associated mortality worldwide, despite the availability of a variety of therapeutic strategies $(1,2)$. Ulcerative colitis (UC) is a serious inflammatory bowel disease in humans and has been demonstrated to be a high-risk factor for CRC $(3,4)$. Thus, the early diagnosis and treatment of UC may delay its progression to CRC. Furthermore, lifestyle and diet each serve an important role in the aetiology of cancer at the majority of sites $(5,6)$. Specifically, high intakes of red meat, fat and carbohydrates have been suggested to increase the risk of CRC (7). By contrast, lactoferrin (LF), fruit, vegetable and fibre intake may reduce the risk of developing CRC (8). Therefore, altering dietary habits and consuming appropriate foods may serve as a novel therapeutic strategy for the prevention of human cancer.

$\mathrm{LF}$ is an $80 \mathrm{kDa}$ iron-binding, single-chain glycoprotein that was first purified from human milk (9). It is expressed in the secretory granules of neutrophils and in various secretory fluids, including milk, tears, nasal fluids, saliva, pancreatic fluids and gastrointestinal fluids (10). LF has been reported to exert a wide range of physiological functions, including anticancer, antimicrobial, anti-inflammatory and immune regulatory activities $(11,12)$. In addition, previous studies have observed that bLF induces the suppression of proliferation in various types of cancer cells in vitro (13-16). The carcinogen 1,2-dimethylhydrazine (DMH) is widely used to induce CRC in animal models (17). DMH also induces the formation of aberrant cryptic foci, which are involved in the multistep pathogenesis of colon cancer (18). Dextran sulphate sodium (DSS) is a synthesised sulphated polyglucan that has previously been used to induce gut inflammation and colitis in animal models $(19,20)$.

In the present study, the aim was to comprehensively evaluate the effect of liposomal bovine LF (LbLF), which is covered in soybean lecithin and exhibits improved stability in the stomach and enhanced absorption by the intestinal tract than bLF, on DMH-induced colorectal cancer following treatment with DSS in F344 rats. 


\section{Materials and methods}

Preparation of $L b L F$. The test sample, which consisted of multi-lamellar vesicles, was prepared by hydrating dietary soy phosphatidylcholine with an aqueous solution containing bLF. Briefly, $10.2 \%(\mathrm{w} / \mathrm{w})$ soy phosphatidylcholine solubilised in glycerine and $19.8 \%(\mathrm{w} / \mathrm{w})$ bLF were mixed at a ratio of 1.00:1.54, and emulsified (R\&D Division, Sunstar Inc., Osaka, Japan). The emulsified solution was then liposomalised using a high-pressure homogenizer. The diameter of the liposomes was determined using a particle size analyser, and the mean diameter was $\sim 70 \mathrm{~nm}$. The control solution (glycerine) was prepared in a similar manner.

Animals and diet. A total of 36 male 5-week-old F344 rats (weighing 70-90 g) were purchased from Charles River Laboratories Japan, Inc. (Yokohama, Japan). The animals were cared for in compliance with the principles and guidelines of the Ethical Committee for Animal Care of the Prefectural University of Hiroshima (Hiroshima, Japan) and the Prefectural University of Hiroshima Animal Ethics Committee in accordance with the Japanese National Law on Animal Care and Use. The Ethical Committee for Animal Care of the Prefectural University of Hiroshima (Hiroshima, Japan) approved the experiments undertaken. The rats were housed in an air-conditioned room at the Laboratory Animal Research Centre of the Prefectural University of Hiroshima, Japan. The room provided a 12-h light/dark cycle, a controlled ambient temperature of $23 \pm 2^{\circ} \mathrm{C}$ and a humidity of $50 \pm 10 \%$. The rats had free access to drinking water and were fed a moderate fat basal diet (Oriental Yeast Co., Ltd., Tokyo, Japan).

Experimental protocol. DMH (Tokyo Chemical Industry Co., Ltd., Tokyo, Japan) was dissolved in $0.9 \% \mathrm{NaCl}$ solution, and the $\mathrm{pH}$ was adjusted to $6.5 \mathrm{using} \mathrm{NaHCO}_{3}$. As indicated in Fig. 1, the drinking water of all 36 rats was supplemented with $1 \%$ DSS for one week (week-1), starting at 5 weeks of age. Upon reaching 6 weeks of age (week 0 ), the rats were randomly allocated into three groups of 12 rats each. Each group received water (control), 500 or $1,000 \mathrm{mg} / \mathrm{kg} /$ day LbLF from week 0-25. All rats were injected with DMH ( $20 \mathrm{mg} / \mathrm{kg}$ body weight) once per week for 8 consecutive weeks (weeks 0-8). The body weights and LbLF dilution intake of the rats were recorded every week to determine the correct dose of LbLF. All rats were sacrificed by anaesthesia $(45 \mathrm{mg} / \mathrm{kg}$ body weight of sodium pentobarbital). 25 weeks following the commencement of DMH administration to allow for tissue examination.

Analysis of aberrant crypt foci (ACF). After the rats were sacrificed, the colons were quickly removed, flushed with saline solution and opened longitudinally from the cecum to the anus. The colons were placed on a paper towel and fixed in $10 \%$ buffered formalin for $24 \mathrm{~h}$ at room temperature. They were stained with $0.5 \%$ methylene blue for 15-30 min at room temperature and then placed on a glass slide, with the luminal side facing up. The stained colons were observed under a light microscope at a magnification of $\mathrm{x} 20-30$. The number of ACFs was recorded.

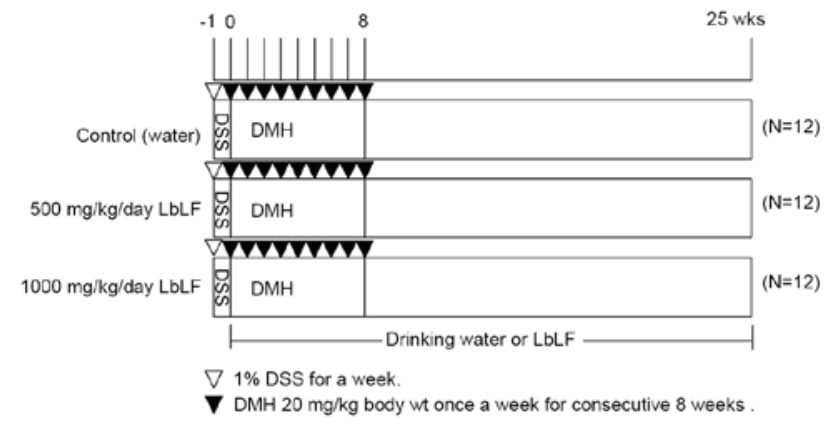

Figure 1. Carcinogenesis experimental protocol. The control group rats received subcutaneous injections of $20 \mathrm{mg} / \mathrm{kg}$ body weight DMH once per week for 8 weeks (from 0 week to 8 week), following the administration of $1 \%$ DSS in the drinking water for one week (from -1 week to 0 week), and additionally received 500 or $1,000 \mathrm{mg} / \mathrm{kg} /$ day LbLF in the drinking water, respectively, starting at week 0 to 25 . All rats were sacrificed after 25 weeks. DMH, 1,2-dimethylhydrazine; DSS, dextran sulphate sodium; LbLF, liposomal bovine lactoferrin.

Histological analysis. After the ACFs had been recorded, the $10 \%$ buffered formalin-fixed colons were embedded in paraffin, sectioned at a thickness of $4 \mu \mathrm{m}$, stained with haematoxylin and eosin (H\&E) and examined under a light microscope (magnification, x100; Olympus Corporation, Tokyo, Japan). The counted tumours were classified into two types: Adenomas (including mild, moderate or severe dysplasia categorisations) and adenocarcinomas (including well, moderately or poorly differentiated tubular adenocarcinoma, signet ring cell or mucinous carcinoma categorisations).

Cell lines and cell culture. RKO and RCN-9 human CRC cells, provided by the Japanese Collection of Research Bioresources Cell Bank (Ibaraki, Japan), were cultured in Dulbecco's modified Eagle's medium (DMEM; Invitrogen; Thermo Fisher Scientific, Inc., Waltham, MA, USA) containing $10 \%$ fetal bovine serum (FBS; Invitrogen; Thermo Fisher Scientific, Inc.) and $100 \mathrm{U} / \mathrm{ml}$ penicillin-streptomycin at $37^{\circ} \mathrm{C}$ in a humidified atmosphere of $5 \% \mathrm{CO}_{2}$. For the growth assay, $5 \times 10^{3}$ cells were plated onto 24 -well plates (Falcon; Corning Incorporated, Corning, NY, USA) and cultured in DMEM with $10 \% \mathrm{FBS}$ at $37^{\circ} \mathrm{C}$ in a humidified atmosphere of $5 \% \mathrm{CO}_{2}$. Subsequently, trypsinized cells were counted at $0,1,2$, and 3 days using a Cell Counter (Coulter Z1, Coulter Co., Hialeah, FL, USA).

Gene expression experiments. RKO and RCN-9 cells were seeded into $60-\mathrm{mm}$ culture dishes $\left(5 \times 10^{5}\right.$ cells/well $)$ and cultured in DMEM supplemented with $10 \%$ FBS as aforementioned. The cells were then cultured in fresh DMEM supplemented with $10 \%$ FBS with or without lipopolysaccharide (A.a-LPS; $100 \mathrm{ng} / \mathrm{ml}$ ), LPS from Aggregatibactor Actinomycetemcomitance (ATCC29522 strain; A.a.-LPS) was provided by Professor Tatsuji Nishihara of the Kyusyu Dental College (Kyusyu, Japan). The cultured cells were harvested 0, 2, 4 and $6 \mathrm{~h}$ after LPS stimulation. The expression level of TNF $\alpha$ mRNA was determined. Furthermore, following a 4-h treatment with $\operatorname{LbLF}(1,10$ or $100 \mu \mathrm{g} / \mathrm{ml})$ or a control treatment (no LbLF) at $37^{\circ} \mathrm{C}$ in a humidified atmosphere of $5 \% \mathrm{CO}_{2}$, the culture plates were briefly washed 


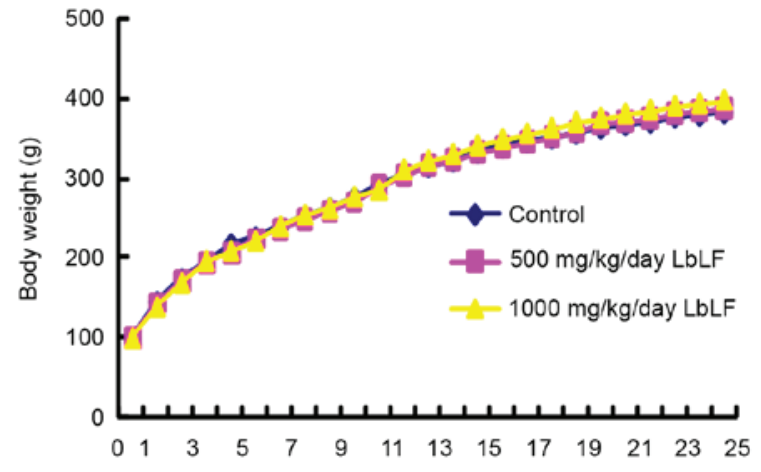

Figure 2. Change of body weights in the control and LbLF group rats. LbLF, liposomal bovine lactoferrin.

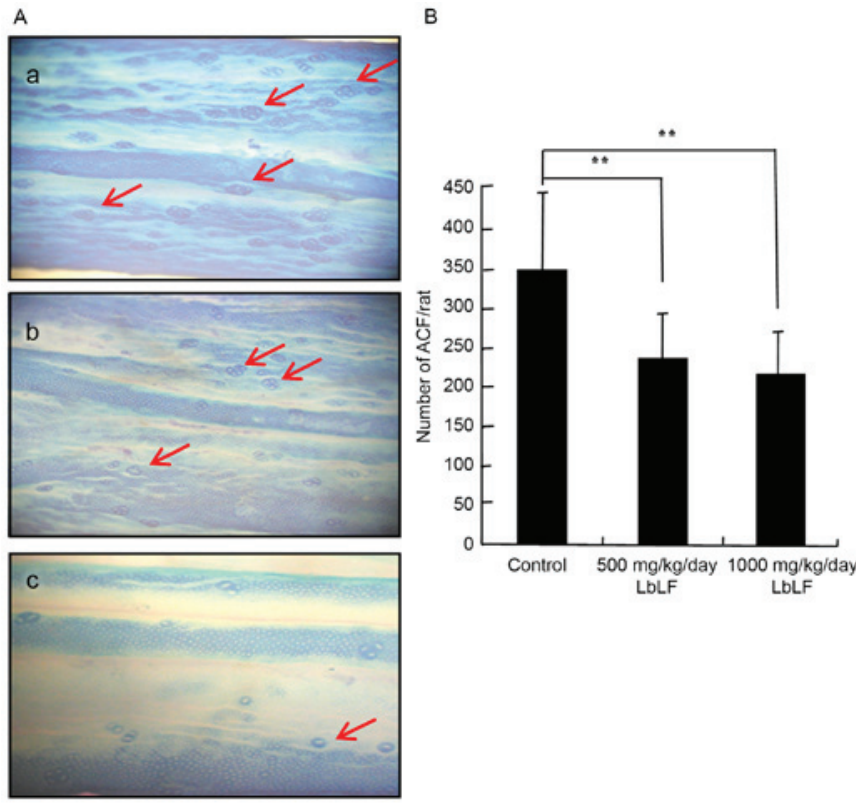

Figure 3. ACF expression in the colons of rats treated with DMH-DSS (A) Representative images of ACF expression in the colons of rats treated with DMH-DSS and stained with $0.5 \%$ methylene blue: a) ACF expression in the colon from a rat in the control group, b) ACF expression in the colon of a rat in the $500 \mathrm{mg} / \mathrm{kg} / \mathrm{day}$ LbLF group, c) ACF expression in the colon of a rat in the $1,000 \mathrm{mg} / \mathrm{kg} / \mathrm{day}$ LbLF group. Arrows indicate ACFs in the colon. (B) Number of ACFs in the colons of rats treated with DMH-DSS. ${ }^{* *} \mathrm{P}<0.01$, compared with the control group. ACF, aberrant crypt foci; DMH-DSS, 1,2-dimethylhydrazine and dextran sulphate sodium; LbLF, liposomal bovine lactoferrin.

twice with PBS and the cells were incubated with A.a.-LPS $(100 \mathrm{ng} / \mathrm{ml})$ with or without a 2 -h pre-treatment. The cultured cells were collected and expression level of TNF $\alpha$ mRNA was evaluated.

Reverse transcription-polymerase chain reaction (RT-PCR). The total RNA from the harvested fully confluent cells was isolated using an RNeasy Mini kit (Qiagen $\mathrm{GmbH}$, Hilden, Germany). An ultramicro spectrophotometer (ND-2000: NanoDrop 2000; Thermo Scientific, Inc., ) was used to detect the concentration of RNA. The cDNA was synthesized from $1 \mu \mathrm{g}$ of total RNA was produced using a transcriptase PCR kit (ReverTra Dash; Toyobo Biochemicals, Osaka, Japan)
Table I. Number of macroscopically evident ACFs.

\begin{tabular}{lcc}
\hline $\begin{array}{l}\text { LbLF dose, } \\
\mathrm{mg} / \mathrm{kg} / \text { day }\end{array}$ & Rats, $\mathrm{n}$ & $\begin{array}{c}\text { ACF (n, } \\
\text { mean } \pm \text { standard deviation) }\end{array}$ \\
\hline 0 (control) & 12 & $352.9 \pm 94.3$ \\
500 & 12 & $236.6 \pm 57.5^{\mathrm{a}}$ \\
1,000 & 12 & $215.1 \pm 54.2^{\mathrm{a}}$ \\
\hline
\end{tabular}

${ }^{\mathrm{a}} \mathrm{P}<0.01$ vs. control group. ACF, aberrant crypt foci; LbLF, liposomal bovine lactoferrin.

according to the manufacturer's protocol. The following primers were used: Human tumour necrosis factor $\alpha(\mathrm{TNF} \alpha)$ : 5'-GCCCATGTTGTAGCAAACC-3', forward and 5'-CCA AAGTAGACCTGCCCAGA-3', reverse (product size, 239 bp); human GAPDH: 5'-TCCACCACCCTGTTGCTG TA-3', forward and 5'-ACCACAGTCCATGCCATCAC-3', reverse. Aliquots of total cDNA $(0.05 \mu \mathrm{g})$ were amplified with $1.25 \mathrm{U}$ rTaq-DNA Polymerase (Qiagen $\mathrm{GmbH}$ ) in a thermal cycler (MyCyler; Bio-Rad Laboratories, Inc., Hercules, CA). The PCR protocol for all primers consisted of 30 cycles of the following: An initial $30 \mathrm{sec}$ of denaturation at $94^{\circ} \mathrm{C}$, annealing for $30 \mathrm{sec}$ at $60^{\circ} \mathrm{C}$ and extension for $1 \mathrm{~min}$ at $72^{\circ} \mathrm{C}$. The amplification reaction products were resolved on $1.2 \%$ agarose/Tris-acetate-EDTA gels (Nacalai Tesque, Inc., Kyoto, Japan). The final PCR products were separated by electrophoresis on $1.2 \%$ agarose gels at $100 \mathrm{mV}$ for $20-40 \mathrm{~min}$ and visualised using ethidium bromide.

Statistical analysis. The Statcel software package (KaleidaGraph version 4.1, Reading, PA, USA), was used for statistical analysis. The data in the current study are presented as means \pm standard error. The significance differences between control group and LbLF group in the in vivo and in vitro experiments were evaluated using unpaired Student's t-tests. $\mathrm{P}<0.05$ was considered to indicate a statistically significant difference.

\section{Results}

Body weight. Fig. 2 presents the body weight of rats from the three groups measured during the experiment. Upon reaching 6 weeks of age (defined as week 0 ), the rats were randomly allocated into 3 groups of 12 rats. Each group received water (control), 500 or $1,000 \mathrm{mg} / \mathrm{kg} /$ day LbLF from week $0-25$. The body weights of the rats were recorded every week. Groups of rats were compared for body weight from week 0-25. Body weight was not observed to significantly differ between any of the groups of rats at any point of the experiment.

Total number of colonic ACFs. The inhibitory influence of LbLF on the growth and development of DMH-induced total number of colonic ACF in rats is presented in Fig. 3 and Table I. ACF expression in the colons of rats treated with DMH-DSS was analysed using $0.5 \%$ methylene blue stain (Fig. 3A). Rats treated with DMH exhibited a $100 \%$ incidence of ACF. Furthermore, the mean number of ACF was significantly lower 
Table II. Number of colon adenomas per rat.

Adenomas per rat (mean \pm standard deviation)

\begin{tabular}{|c|c|c|c|c|c|}
\hline \multirow[b]{2}{*}{ LbLF dose, mg/kg/day } & \multirow[b]{2}{*}{ Rats, n } & \\
\hline & & Total & Mild atypia & Moderate atypia & Severe atypia \\
\hline 0 (control) & 12 & $33.7 \pm 12.91$ & $22.9 \pm 10.39$ & $9.2 \pm 3.54$ & $1.6 \pm 1.68$ \\
\hline 500 & 12 & $23.6 \pm 7.86^{\mathrm{a}}$ & $17.1 \pm 5.01$ & $5.5 \pm 3.26^{\mathrm{a}}$ & $0.9 \pm 1.44$ \\
\hline 1,000 & 12 & $17.1 \pm 5.81^{\mathrm{b}}$ & $13.3 \pm 5.10^{\mathrm{b}}$ & $3.6 \pm 2.23^{b}$ & $0.3 \pm 0.45^{\mathrm{a}}$ \\
\hline
\end{tabular}

${ }^{\mathrm{a}} \mathrm{P}<0.05,{ }^{\mathrm{b}} \mathrm{P}<0.01$ vs. control. LbLF, liposomal bovine lactoferrin.
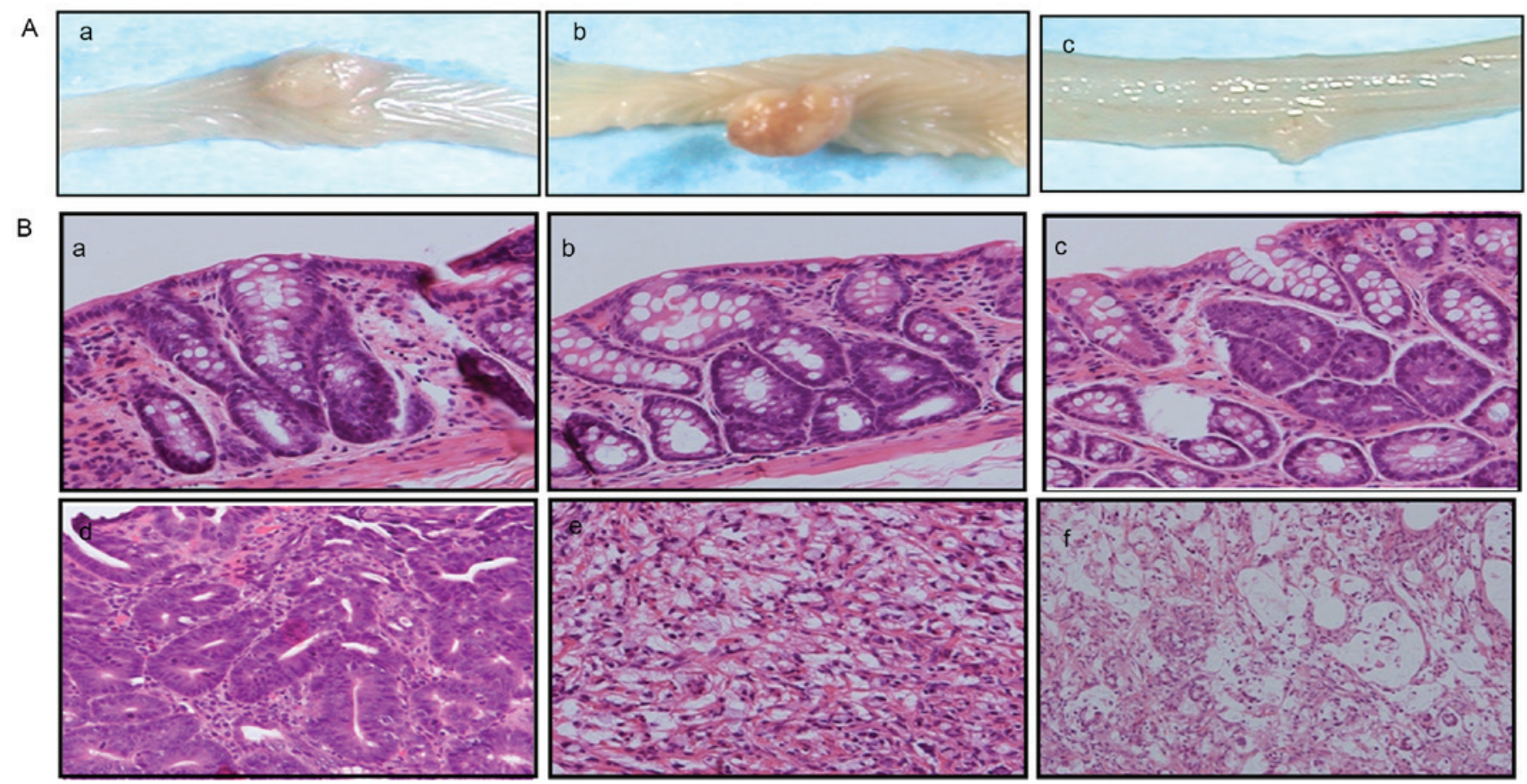

Figure 4. Macroscopic and histological features of the DMH-treated rat colons. (A) Gross features of macroscopic tumours in the colon: a) Tumour in the colon of a rat in the control group, b) tumour in the colon of a rat in the $500 \mathrm{mg} / \mathrm{kg} / \mathrm{day} \mathrm{LbLF}$ group, c) tumour in the colon of a rat in the $1,000 \mathrm{mg} / \mathrm{kg} / \mathrm{day} \mathrm{LbLF}$ group. (B) DMH-induced colorectal tumours in rats with haematoxylin and eosin staining: a) Adenoma with mild atypia, b) adenoma with moderate atypia, c) adenoma with severe atypia, d) well-differentiated tubular adenocarcinomas, e) signet ring cell carcinomas, f) Mucinous adenocarcinomas. Haematoxylin and eosin staining (magnification, x200). DMH, 1,2-dimethylhydrazine; LbLF, liposomal bovine lactoferrin.

in the 500 and $1,000 \mathrm{mg} / \mathrm{kg} / \mathrm{day}$ LbLF groups, as compared with in the control group (Fig. 3B; Table I; P<0.01). Arrows indicate the ACFs in the colon (Fig. 3A).

Colon tumours. The colon tissue sections obtained from the rats were subjected to histopathological investigation, and the colon epithelial lesions were classified as adenomas or adenocarcinomas (Fig. 4). Table II indicates that rats from the 500 and $1,000 \mathrm{mg} / \mathrm{kg} /$ day LbLF groups harboured significantly fewer colon adenomas than rats from the control group (500 mg/kg/day, $\mathrm{P}<0.05 ; 1,000 \mathrm{mg} / \mathrm{kg} /$ day, $\mathrm{P}<0.01$ ). The mean \pm standard deviation $(\mathrm{SD})$ of adenomas identified in the control, 500 and 1,000 $\mathrm{mg} / \mathrm{kg} /$ day LbLF groups were $33.70 \pm 12.91,23.60 \pm 7.86$ and $17.10 \pm 5.81$, respectively. Table II also demonstrates that rats from the 500 and $1,000 \mathrm{mg} / \mathrm{kg} /$ day LbLF groups harboured significantly fewer colon adenomas with moderate atypia than rats from the control group (500 mg/kg/day, $\mathrm{P}<0.05 ; 1,000 \mathrm{mg} / \mathrm{kg} / \mathrm{day}, \mathrm{P}<0.01$ ). Furthermore, rats from the $1,000 \mathrm{mg} / \mathrm{kg} /$ day LbLF group harboured significantly fewer colon adenomas with mild or severe atypia than rats from the control group (mild, $\mathrm{P}<0.01$; severe, $\mathrm{P}<0.05$; Table II).

Table III indicates that the 500 and $1,000 \mathrm{mg} / \mathrm{kg} /$ day LbLF groups harboured significantly fewer colon adenocarcinomas than rats from the control group $(\mathrm{P}<0.05$ and $\mathrm{P}<0.01$, respectively). In addition, the mean $\pm \mathrm{SD}$ for adenocarcinomas identified in the control, 500 and $1,000 \mathrm{mg} / \mathrm{kg} /$ day LbLF groups were $1.25 \pm 0.62,0.67 \pm 0.65$ and $0.50 \pm 0.67$, respectively. Table III also reveals that rats from the $1,000 \mathrm{mg} / \mathrm{kg} /$ day LbLF group harboured significantly fewer differentiated carcinomas (well and moderate adenocarcinoma; $\mathrm{P}<0.05$ ), but not undifferentiated carcinomas (poorly, mucinous, signet ring cell carcinoma), 
Table III. Number of colon adenocarcinomas per rat.

Adenocarcinomas per rat ( $\mathrm{n}$, mean \pm standard deviation)

\begin{tabular}{lcccc}
\cline { 3 - 5 } LbLF dose, $\mathrm{mg} / \mathrm{kg} / \mathrm{day}$ & Rats, $\mathrm{n}$ & Total & Undifferentiated $^{\mathrm{a}}$ & Differentiated $^{\mathrm{b}}$ \\
\hline 0 (control) & 12 & $15(1.25 \pm 0.62)$ & $6(0.50 \pm 0.52)$ & $9(0.75 \pm 0.75)$ \\
500 & 12 & $7(0.67 \pm 0.65)^{\mathrm{c}}$ & $4(0.33 \pm 0.49)$ & $3(0.25 \pm 0.45)^{\mathrm{c}}$ \\
1,000 & 12 & $6(0.50 \pm 0.67)^{\mathrm{d}}$ & $4(0.33 \pm 0.49)^{\mathrm{c}}$ & $2(0.17 \pm 0.39)$ \\
\hline
\end{tabular}

${ }^{a}$ Includes poorly differentiated adenocarcinomas, and mucinous or signet ring cell carcinomas. ${ }^{\mathrm{b}}$ Includes well and moderately differentiated adenocarcinomas. ${ }^{c} \mathrm{P}<0.05$, ${ }^{\mathrm{d}} \mathrm{P}<0.01$ vs. control. $\mathrm{LbLF}$, liposomal bovine lactoferrin.
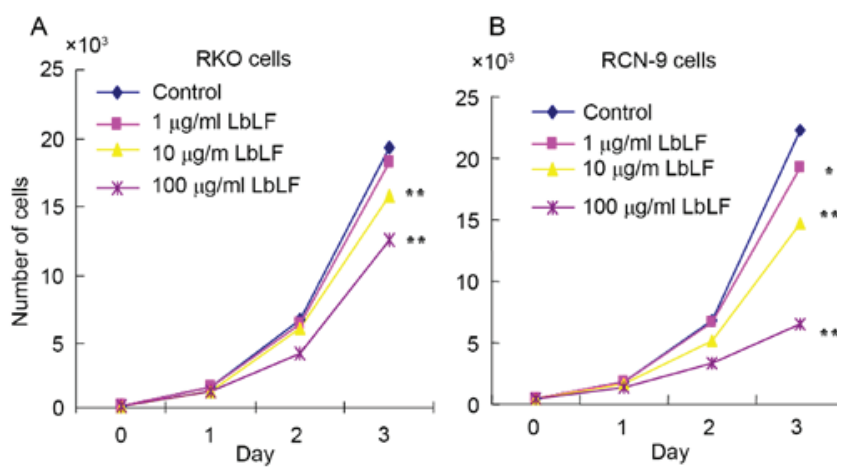

Figure 5. LbLF inhibits the growth of RKO and RCN-9 cells. A total of 5,000 cells were plated into 24-well plates. After $24 \mathrm{~h}$ (day 0), the cell number was counted, and RKO and RCN-9 cells were then pre-incubated with 1 , 10 or $100 \mu \mathrm{g} / \mathrm{ml} \mathrm{LbLF}$. The number of cells were counted on day 1,2 and 3 . ${ }^{*} \mathrm{P}<0.05,{ }^{* *} \mathrm{P}<0.01$, compared with the control group. LbLF, liposomal bovine lactoferrin.

A

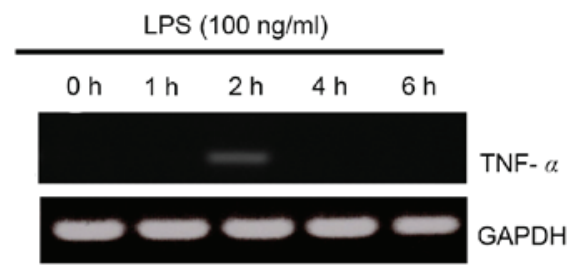

B

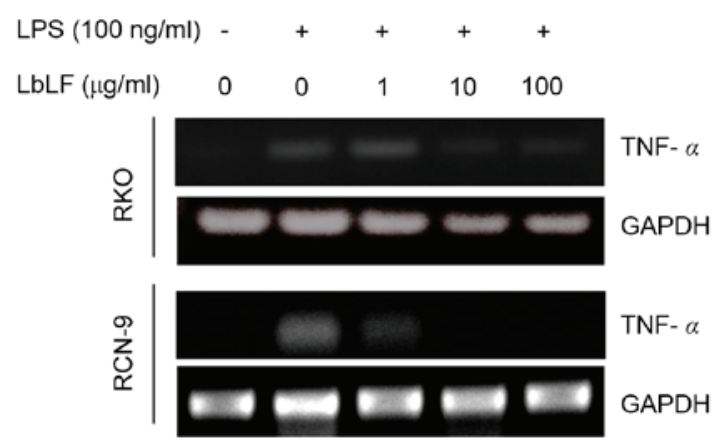

Figure 6. LbLF inhibits TNF- $\alpha$ mRNA expression in RKO and RCN-9 cells. (A) LPS-induced upregulation of TNF- $\alpha$ mRNA expression in RKO cells after $2 \mathrm{~h}$. (B) LbLF inhibited LPS-induced TNF- $\alpha$ mRNA expression in RKO and RCN-9 cells after $2 \mathrm{~h}$. LbLF, liposomal bovine lactoferrin; TNF- $\alpha$, tumour necrosis factor- $\alpha$; LPS, lipopolysaccharide.

compared with rats from the control group. Thus, LbLF for low malignant grade carcinoma inhibition effect is marked.
LbLF inhibits CRC cell growth. The cell growth of LbLF-treated RKO and RCN-9 cells was examined. Compared with the control (no treatment with LbLF), it was observed that treatment with $\geq 10 \mu \mathrm{g} / \mathrm{ml}$ LbLF significantly inhibited the growth of RKO and RCN-9 cells (Fig. 5; P<0.01).

LbLF inhibits TNF- $\alpha$ mRNA expression in CRC cells. The RKO cells were harvested $0,2,4$ and $6 \mathrm{~h}$ following LPS stimulation. The expression levels of TNF $\alpha$ mRNA were determined. LPS was observed to upregulate the expression of TNF- $\alpha$ mRNA in RKO cells after $2 \mathrm{~h}$ (Fig. 6A). Subsequently, treatment with $\operatorname{LbLF}(1,10$ or $100 \mu \mathrm{g} / \mathrm{ml})$ was demonstrated to inhibit TNF- $\alpha$ mRNA expression in CRC cells (RKO and RCN-9 cells). Pre-treatment with a high concentration LbLF (10 or $100 \mu \mathrm{g} / \mathrm{ml}$ ) blocked the LPS-induced upregulation of TNF- $\alpha$ mRNA in RKO and RCN-9 cells (Fig. 6B).

\section{Discussion}

In the present study, LbLF significantly inhibited colon cancer development, suggesting that it may be an effective chemopreventive agent. LF has anticancer, anti-inflammatory and immune regulatory activities $(11,12)$. UC, one of the two major forms of chronic inflammatory bowel disease, was first described in the 1800s (21). This disease is characterised by inflammation-induced chronic destruction and regeneration of colonic mucosa, and is most common in individuals $25-35$ or 55-65 years of age (22). Patients with UC exhibit a high risk of CRC; specifically, this risk is estimated to be $>2-5$ times compared with in the general population $(3,23,24)$. DMH treatment induced oxidative stress and the early inflammatory and tumour promotion responses in the colons of Wistar rats (25).

DSS is a synthetic sulphated polyglucan that has previously been used to induce inflammation in the gut $(19,20)$. Inflammation serves an important role in tumour initiation and promotion (26). TNF- $\alpha$ is a cytokine released by macrophages in response to infection and various other stress conditions (27). The results of the present study demonstrate that LbLF inhibits the LPS-induced upregulation of TNF- $\alpha$ mRNA expression. In our previous study, it was revealed that orally administered LbLF significantly inhibits LPS-induced alveolar bone resorption (28). We also previously demonstrated the anti-inflammatory effect of LF (29), and other studies have observed that LF may interact with epithelial and immune cells in the intestinal mucosa $(30,31)$. Furthermore, the levels of LF 
increase markedly during inflammation (32); LF is important as it may promote or inhibit the inflammatory response (33). Angiogenesis is also associated with inflammatory disease via similar mechanisms (34), and LF may inhibit angiogenesis (35). The findings of the present study suggest that LbLF has an influence against tumour promotion by DMH-DSS; this may be a cause for the observed anti-carcinogenic effect of LbLF.

LbLF exhibits not only anti-inflammatory functions, but also anticancer functions. The results of the present study revealed that rats from the 500 and $1,000 \mathrm{mg} / \mathrm{kg} / \mathrm{day} \mathrm{LbLF}$ groups harbour significantly fewer ACF, adenomas and adenocarcinomas of the colon, compared with rats from the control group. In addition, a number of previous reports indicated that bLF is associated with the inhibition of tumour growth and the prevention of carcinogenesis in vivo and in vitro (13-16). The initial observation that bLF could inhibit tumorigenesis was made in 1995; the whey fraction of bovine milk was demonstrated to inhibit the development of DMH induced colon tumours in rats (36). Other studies have indicated that the incidence of adenocarcinomas in the large intestine induced by azoxymethane in rats was significantly decreased in the bLF-fed group, as compared with in the control group (14). However, there is currently no reported evidence that bLF can inhibit the development of colon cancer in animals.

In a previous human study, a randomised and controlled clinical trial was conducted in the National Cancer Center Hospital (Tokyo, Japan) in order to determine whether the ingestion of bLF had an effect on the growth of colorectal polyps in humans; daily ingestion of $3 \mathrm{~g}$ bLF suppressed the growth of colorectal polyps and increased the levels of serum human LF in the trial participants (37). bLF is hypothesised to inhibit cancer via its ability to bind iron (38). A previous study indicated that the immunostimulation of LF, which activates a $\mathrm{T}$ helper cell type 1 response, and the release of anticancer killer cells may be key factors in the anticancer effect of bLF (25). In addition, LF may also prevent cancer by regulating the expression of certain cell-cycle proteins (39). The results of the present study demonstrated that LbLF inhibits RKO and RCN-9 cell growth. LF may also serve an important role in delaying the development of tumours by acting as an inhibitor of angiogenesis (35). Although the mechanisms by which LF inhibits cancer are not yet fully understood, its anticancer activity is apparent.

In conclusion, the present study described the effects of LbLF on colorectal carcinogenesis in rats. Thus, the present study intended to explore the preventive and therapeutic value of LbLF in CRC. Nevertheless, additional studies are required to confirm these findings and explore the potential underlying mechanisms by which LF affects cancer.

\section{Acknowledgements}

This study was supported in part by The National Natural Science Foundation of China (grant nos. 81460411 and 81160256) and the Guangxi University of Science and Technology Research Projects (grant no. ZD20140094).

\section{References}

1. Klimczak A, Kempińska-Mirosławska B, Mik M, Dziki L and Dziki A: Incidence of colorectal cancer in Poland in 1999-2008. Arch Med Sci 7: 673-678, 2011.
2. Ferlay J, Steliarova-Foucher E, Lortet-Tieulent J, Rosso S, Coebergh JW, Comber H, Forman D and Bray F: Cancer incidence and mortality patterns in Europe: Estimates for 40 countries in 2012. Eur J Cancer 49: 1374-1403, 2013.

3. Jewell DP, Chapman RGW and Mortensen N: Ulcerative colitis and Crohn's disease, a clinician's guide. London: Churchill. Livingstone 79, 1992.

4. Efthymiou M, Taylor AC and Kamm MA: Cancer surveillance strategies in ulcerative colitis. The need for modernization. Inflmm Bowel Dis 17: 1800-1813, 2011.

5. Doll R and Peto R: The causes of cancer: Quantitative estimates of avoidable risks of cancer in the United States today. J Natl Cancer Inst 66: 1193-1308, 1981.

6. Willett WC: Diet, nutrition, and avoidable cancer. Environ Health Perspect 103 (Suppl 8): 165-170, 1995.

7. Willett WC, Stampfer MJ, Colditz GA, Rosner BA and Speizer FE: Relation of meat, fat, and fiber intake to the risk of colon cancer in a prospective study among women. N Engl J Med 323: 1664-1672, 1990.

8. Chan AT and Giovannucc EL: Primary prevention of colorectal cancer. Gastroenterology 138: 2029-2043.e10, 2010.

9. Farnaud S and Evans RW: Lactoferrin-a multifunctional protein with antimicrobial properties. Mol Immunol 40: 395-405, 2003.

10. Fleet JC: A new role for lactoferrin: DNA binding and transcription activation. Nutr Rev 53: 226-227, 1995.

11. Gibson RJ and Bowen JM: Biomarkers of regimen-related mucosal injury. Cancer Treat Rev 37: 487-493, 2011.

12. de Mejia EG and Dia VP: The role of nutraceutical proteins and peptides in apoptosis, angiogenesis, and metastasis of cancer cells. Cancer Metastasis Rev 29: 511-528, 2010.

13. Li D, Sakashita S, Morishita Y, Kano J, Shiba A, Sato T and Noguchi M: Binding of lactoferrin to IGBP1 triggers apoptosis in a lung adenocarcinoma cell line. Anticancer Res 31: 529-534, 2011.

14. Tsuda H, Sekine K, Nakamura J, Ushida Y, Kuhara T, Takasuka N Kim DJ, Asamoto M, Baba-Toriyama H, Moore MA, et al: Inhibition of azoxymethane initiated colon tumor and aberrant crypt foci development by bovine lactoferrin administration in F344 rats. Adv Exp Med Biol 443: 273-284, 1998.

15. Masuda C, Wanibuchi H, Sekine K, Yano Y, Otan S, Kishimoto T, Tsuda H and Fukushima S: Chemopreventive effects of bovine lactoferrin on N-butyl-N-(4-hydroxybutyl)nitrosamine-induced rat bladder carcinogenesis. Jpn J Cancer Res 91: 582-588, 2000.

16. Ushida Y, Sekine K, Kuhara T, Takasuka N, Iigo M, Maeda M and Tsuda H: Possible chemopreventive effects of bovine lactoferrin on esophagus and lung carcinogenesis in the rat. Jpn J Cancer Res 90: 262-267, 1999.

17. Baskar AA, Ignacimuthu S, Paulraj GM and Al Numair KS: Chemopreventive potential of beta-sitosterol in experimental colon cancer model-an in vitro and in vivo study. BMC Complement Altern Med 10: 24, 2010.

18. Hamiza OO, Rehman MU, Tahir M, Khan R, Khan AQ, Lateef A, Ali F and Sultana S: Amelioration of 1,2 dimethylhydrazine $(\mathrm{DMH})$ induced colon oxidative stress, inflammation and tumor promotion response by tannic acid in Wistar rats. Asian Pac J Cancer Prev 13: 4393-4402, 2012.

19. Axelsson LG and Ahlstedt S: Actions of sulphasalazine and analogues in animal models of experimental colitis. Inflammopharmacology 2: 219-232, 1993.

20. Okayasu I, Hatakeyama S, Yamada M, Ohkusa T, Inagaki Y and Nakaya R: A novel method in the induction of reliable experimental acute and chronic ulcerative colitis in mice. Gastroenterology 98: 694-702, 1990.

21. Wilks S: Morbid appearances in the intestine of Miss Bankes. London Medical Times \& Gazette 2: 264, 1859.

22. Hou JK, Kramer JR, Richardson P, Mei M and El-Serag HB: The incidence and prevalence of inflammatory bowel disease among U.S, veterans: A national cohort study. Inflamm Bowel Dis 19: 1059-1064, 2013.

23. Ekbom A, Helmick C, Zack M and Adami HO: Ulcerative colitis and colorectal cancer. A population-based study. N Engl J Med 323: 1228-1233, 1990.

24. Bernstein CN, Blanchard JF, Kliewer E and Wajda A: Cancer risk in patients with inflmmatory bowel disease: A population-based study. Cancer 91: 854-862, 2001.

25. Fischer R, Debbabi H, Dubarry M, Boyaka P and Tomé D: Regulation of physiological and pathological Th1 and Th2 responses by lactoferrin. Biochem Cell Biol 84: 303-311, 2006. 
26. Qi G,Zeng S, Takashima T,Nozoe K, Shobayashi M,Kakugawa K, Murakami K, Jikihara H, Zhou L and Shimamoto F: Inhibitory Effect of Various Breads on DMH-Induced Aberrant Crypt Foci and Colorectal Tumours in Rats. Biomed Res Int 2015: 829096, 2015.

27. Blackwell TS and Christman JW: Sepsis and cytokines: Current status. Br J Anaesth 77: 110-117, 1996.

28. Kawazoe A, Inubushi T, Miyauchi M, Ishikado A, Tanaka E, Tanne K and Takata T: Orally administered liposomal lactoferrin inhibits inflammation-related bone breakdown without interrupting orthodontic tooth movement. J Periodontol 84: 1454-1462, 2013.

29. Inubushi T, Kawazoe A, Miyauchi M, Kudo Y, Ao M, Ishikado A, Makino T and Takata T: Molecular mechanisms of the inhibitory effects of bovine lactoferrin on lipopolysaccharide-mediated osteoclastogenesis. J Biol Chem 287: 23527-23536, 2012.

30. Damiens E, Mazurier J, Yazidi I, Masson M, Duthille I, Spik G and Boilly-Marer Y: Effects of human lactoferrin on NK cell cytotoxicity against haematopoietic and epithelial tumour cells. Biochim Biophys Acta 1402: 277-287, 1998.

31. Shau H, Kim A and Golub SH: Modulation of natural killer and lymphokine-activated killer cell cytotoxicity by lactoferrin. J Leukoc Biol 51: 343-349, 1992.

32. Casado B, Pannell LK, Iadarola P and Baraniuk JN: Identification of human nasal mucous proteins using proteomics. Proteomics 5 2949-2959, 2005.
33. Legrand D and Mazurier J: A critical review of the roles of host lactoferrin in Immunity. Biometals 23: 365-376, 2010.

34. Rajashekhar G, Willuweit A, Patterson CE, Sun P, Hilbig A Breier G, Helisch A and Clauss M: Continuous endothelial cell activation increases angiogenesis: Evidence for the direct role of endothelium linking angiogenesis and inflammation. J Vasc Res 43: 193-204, 2006.

35. Parodi PW: A role for milk proteins and their peptides in cancer prevention. Curr Pharm Des 13: 813-828, 2007.

36. Levay PF and Viljoen M: Lactoferrin: A general review. Haematologica 80: 252-267, 1995.

37. Iigo M, Alexander DB, Xu J, Futakuchi M, Suzui M, Kozu T, Akasu T, Saito D, Kakizoe T, Yamauchi K, et al: Inhibition of intestinal polyp growth by oral ingestion of bovine lactoferrin and immune cells in the large intestine. Biometals 27: 1017-1029, 2014.

38. González-Chávez SA, Arévalo-Gallegos S and Rascón-Cruz Q: Lactoferrin: Structure, function and applications. Int J Antimicrob Agents 33: 301.e1-8, 2009 .

39. Rodrigues L, Teixeira J, Schmitt F, Paulsson M and Månsson HL: Lactoferrin and cancer disease prevention. Crit Rev Food Sci Nutr 49: 203-217, 2009. 